\title{
A new design of stepped antenna loaded metamaterial for RFID applications
}

\author{
Badr Nasiri, Ahmed Errkik, Jamal Zbitou
}

LMIET, Faculty of Sciences and Technics, Hassan first University, Morocco

\begin{tabular}{|c|c|}
\hline Article Info & ABSTRACT \\
\hline Article history: & \multirow{9}{*}{$\begin{array}{l}\text { Radio frequency identification is being overloaded with data information, } \\
\text { making wideband band antennas very appealing. In this paper, we present a } \\
\text { new design of dual band antenna for RFID reader applications operating at } \\
2.45 \mathrm{Gz} \text { and } 5.8 \mathrm{GHz} \text { with an average gain of } 1.16 \mathrm{~dB} \text { at the lower frequency } \\
\text { band and } 3.2 \mathrm{~dB} \text { at the higher frequency band. The antenna is designed on an } \\
\text { FR-4 substrate having a relative dielectric constant of } 4.4 \text { and loss tangent of } \\
0.025 \text {. The proposed antenna is simulated, designed and, optimized using CST } \\
\text { Microwave Studio and has a small size of } 32 \mathrm{~mm} \times 26 \mathrm{~mm} \times 1.6 \mathrm{~mm} \text {. The } \\
\text { antenna consists of a steeped rectangular patch antenna using a partial ground } \\
\text { plane loaded a modified split ring resonator. The metamaterial structure was } \\
\text { designed and optimized to operate at } 2.45 \mathrm{GHz} \text { and its effective parameters } \\
\text { was verified using the Nicolson-Ross Weir method. The performance of the } \\
\text { proposed antenna is confirmed by another } 3 \mathrm{D} \text { electromagnetic solver HFSS. }\end{array}$} \\
\hline Received Jun 12, 2020 & \\
\hline Revised Apr 29, 2021 & \\
\hline Accepted Aug 18, 2021 & \\
\hline Keywords: & \\
\hline Metamaterial & \\
\hline Microstrip antenna & \\
\hline RFID antenna & \\
\hline SRR & \\
\hline
\end{tabular}

This is an open access article under the $\underline{C C B Y-S A}$ license.

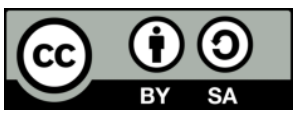

Corresponding Author:

Badr Nasiri

Laboratory of Mechanic, Informatics, Electronic and Telecommunication

Hassan 1st University

FST de Settat, Km 3, B.P. : 577 Route de Casablanca, Settat, Morocco

Email: b.nasiri@uhp.ac.ma

\section{INTRODUCTION}

In recent years, the telecommunications field has known an extremely rapid development. This development driven by strong demand from industry and consumers has led to the emergence of radio communications circuits. Among these technologies we find the radio frequency identification (RFID) which knows today its full development. It affects several sectors and has a wide range of applications, such as distribution, logistics, security, traceability, identification and so on [1]-[5].

The RFID technology is basically a wireless communication that allows the identification of objects of all types, including humans and animals, by radio waves data capture. The objects are identified thanks to a specific label, called tag, embedded the object to be identified [6]-[8]. Depending on the application, RFID systems operates at different frequencies from the $\mathrm{HF}$ band around $13 \mathrm{kHz}$ to the microwave band around $2.45 \mathrm{GHz}$ and $5.8 \mathrm{GHz}[9]-[12]$.

Generally, a typical RFID system consists of two main components, a transponder and a reader. The transponder is a device comprising an electronic microchip for storing data and an antenna for communicating with the reader, each tag containing a unique identification information of the tagged object. The reader is a device that communicates with the transponder through an antenna, it can read and write information on the RFID chip. An RFID system can be represented by the block diagram of Figure 1 [13]-[16]. Antennas are a very important factor in communication between reader and tag in RFID systems. They require antennas with good performance and a miniature size; however, it is very difficult to design antennas with good performance and small size at the same time. For this reason, different techniques are 
proposed in many researches to reduce the size of antennas without degrading their performance, such as fractal geometry, the use of slots, folding techniques, and so on. [17]-[21].

In this work, we proposed to use metamaterial structures that are subwavelength structures having some electromagnetic characteristics which do not exist in conventional materials. The rest of this paper is organized as; in the second section, we present de proposed metamaterial structure, in third section, we presented the antenna design and in the last section, the results and discussion will be reported.

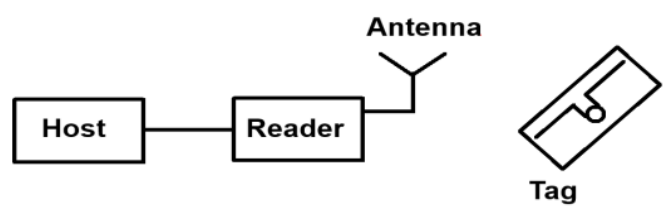

Figure 1. Block diagram of an RFID system

\section{PROPOSED METAMATRIAL STRUCTURE}

Metamaterials are artificial materials with electromagnetic properties that cannot be found in nature. The theoretical concept of metamaterials was introduced for the first time by Veselago in 1968 [22]. But the experimental concept for producing negative permittivity materials from metallic wires was proposed by Pendry et al. in 1996 [23]. Three years later, Pendry and his colleagues proposed to take advantage of the inductive response of the collective electron movement in non-magnetic conductive elements in the form of a split ring resonator (SRR) to achieve a negative permeability [24].

Based on Pendry's work, several publications have studied new structures and analyzed the left-hand behavior of these structures, such as circular, rectangular, triangular, and so on. In this paper, we present a new miniature metamaterial structures based on modified split ring resonators. The proposed structure is illustrated in Figure 2 (a) and its optimized parameters are illustrated in Table 1. In order to verify the metamaterial effect of this structure, it has been introduced into a waveguide box as shown in Figure 2 (b).

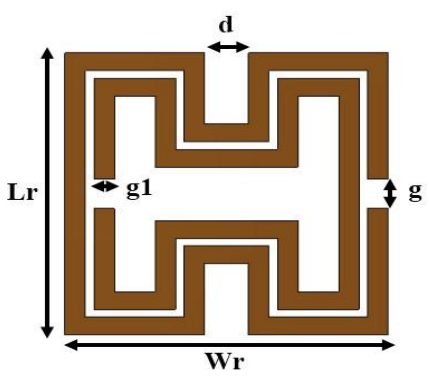

(a)

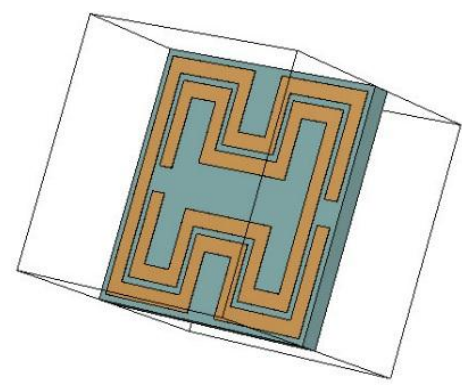

(b)

Figure 2. These figures are; (a) geometry of the proposed metamaterial resonator, (b) proposed metamaterial resonator in a TEM waveguide box

Table 1. Dimensions of the proposed metamaterial resonator parameters

\begin{tabular}{cc}
\hline Parameter & Dimension $(\mathrm{mm})$ \\
\hline $\mathrm{Wr}$ & 19.5 \\
$\mathrm{Lr}$ & 19.5 \\
$\mathrm{~g}$ & 2 \\
$\mathrm{~g} 1$ & 1.2 \\
$\mathrm{~d}$ & 2.6 \\
\hline
\end{tabular}

The simulation results in terms of reflection and transmission coefficients are presented in Figure 3 (a). It is clearly remarkable that this structure works around $2.45 \mathrm{GHz}$ which is the targeted frequency at designing the antenna. The Nicolson Ross Weir method was used to extract the actual parameters. This method makes it possible to extract the permittivity and permeability based on the S-parameters results using the [25]. 


$$
\begin{aligned}
& S_{11}=\frac{i}{2}\left(\frac{1}{z}-z\right) \sin (n k d) \\
& S_{21}=\frac{1}{\cos (n k d)-\frac{i}{2}\left(z+\frac{1}{z}\right) \sin (n k d)} \\
& z=\sqrt{\frac{\left(1+S_{11}\right)^{2}-S_{21}^{2}}{\left(1-S_{11}\right)^{2}-S_{21}^{2}}} \\
& \varepsilon_{\text {eff }}=\frac{n}{z} \text { and } \mu_{\text {eff }}=n z
\end{aligned}
$$

Where $\mathrm{n}$ is the refractive index, $\mathrm{z}$ is the wave impedance, $\mathrm{k}$ is the wave number, $\mathrm{d}$ is the thickness of the metamaterial unit cell, $\varepsilon$ is the electric permittivity, and $\mu$ is the magnetic permeability. The computed results in terms of permittivity are presented in Figure 3 (b). We can notice that the proposed structure presents a negative primitivity between $2 \mathrm{Ghz}$ and $2.5 \mathrm{GHz}$.

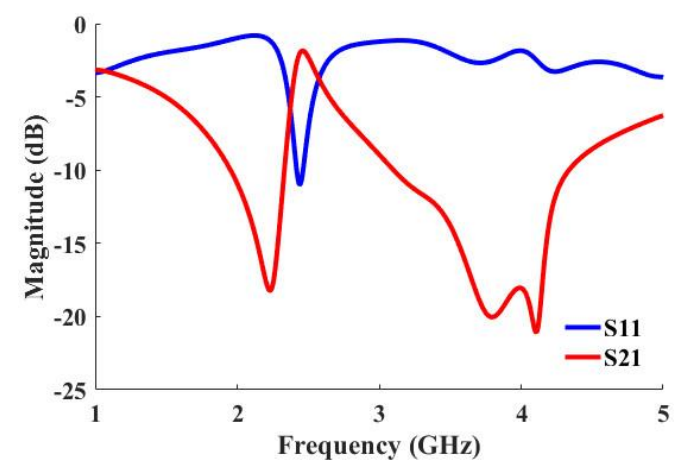

(a)

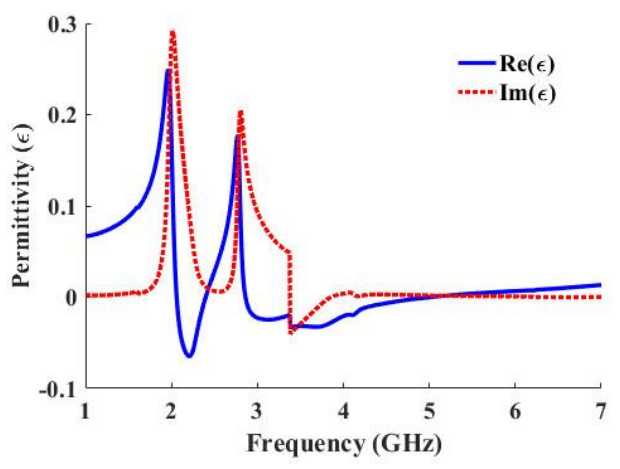

(b)

Figure 3. These figures are; (a) S-parameters of the proposed metamaterial resonator, (b) permittivity of the proposed metamaterial resonator

\section{ANTENNA DESIGN}

The proposed antenna is composed of a rectangular patch with two steps to improve the bandwidth around operating frequencies. The bottom part of the antenna is composed of a partial ground plane loaded by a metamaterial structure in order to reduce the overall size of the antenna. Figure 4 illustrates the proposed antenna geometry. The antenna is designed on an FR-4 substrate having a thickness $\mathrm{H}=1.6 \mathrm{~mm}$, a relative dielectric constant $\varepsilon r=4.4$, and tangent losses $\tan (\delta)=0.025$. The overall size of the proposed antenna is $26 \mathrm{~mm} \times 32 \mathrm{~mm}$ and the metallization thickness is $35 \mu \mathrm{m}$. The operating frequencies of the antenna are $2.45 \mathrm{GHz}$ and $5.8 \mathrm{GHz}$. The optimized antenna parameters are summarized in Table 2.

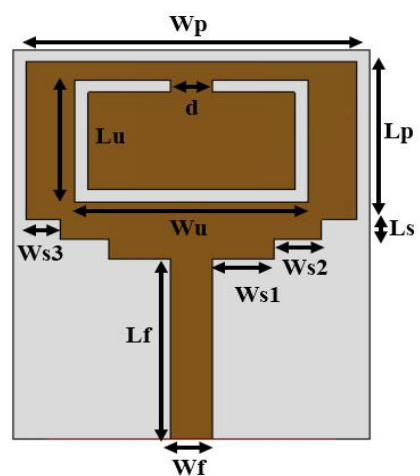

(a)

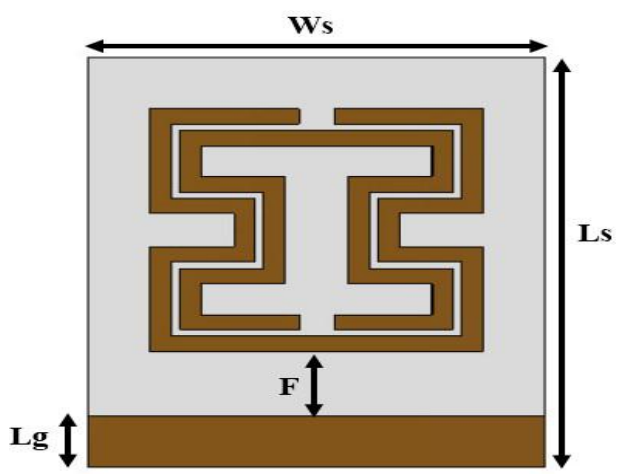

(b)

Figure 4. Geometry of the proposed antenna, (a) top view, (b) bottom view 
Table 2. Dimensions of the proposed antenna

\begin{tabular}{cc}
\hline Parameter & Dimension $(\mathrm{mm})$ \\
\hline $\mathrm{Ws}$ & 26 \\
$\mathrm{Ls}$ & 32 \\
$\mathrm{Wp}$ & 24 \\
$\mathrm{Lp}$ & 13 \\
$\mathrm{Wu}$ & 17 \\
$\mathrm{Lu}$ & 10 \\
$\mathrm{Ws} 1$ & 4.5 \\
Ws 2 & 3.5 \\
Ws3 & 2.5 \\
Ls & 1.6 \\
D & 3 \\
Lf & 18 \\
Wf & 3 \\
Lg & 4 \\
\hline
\end{tabular}

\section{RUSULTS AND DISCUSSION}

The computed results in terms of reflection coefficient are illustrated in Figure 5. As can be seen, this antenna operates around the two bands $2.45 \mathrm{GHz}$ and $5.8 \mathrm{GHz}$ which are regularized for RFID technology. The antenna has a wide bandwidth ranging from $2.4 \mathrm{GHz}$ to $2.66 \mathrm{GHz}$ for the first band and ranging from $5.74 \mathrm{GHz}$ to $6.14 \mathrm{GHz}$ for the second band with a good impedance matching about $-25 \mathrm{~dB}$ around $2.45 \mathrm{Ghz}$ and $-46 \mathrm{~dB}$ around $5.8 \mathrm{GHz}$.

The radiating patterns of the antenna in the E and H planes are shown in Figures 6 and 7. It is noted that two radiation sides are favored, radiation in front of the antenna due to the patch and radiation in the back of the antenna is due to the metamaterial structure. The surface current distribution is plotted in Figure 8. It is remarkable that the maximum of the surface currents is around the open ring and the steps at the bottom of the patch at $5.8 \mathrm{GHz}$ and it is maximal around the metamaterial cell at $2.45 \mathrm{GHz}$. The gain over the frequency of this antenna is plotted in Figure 9. It has a good gain of $1.3 \mathrm{~dB}$ at the first resonance frequency and $3.8 \mathrm{~dB}$ at the second resonance frequency.

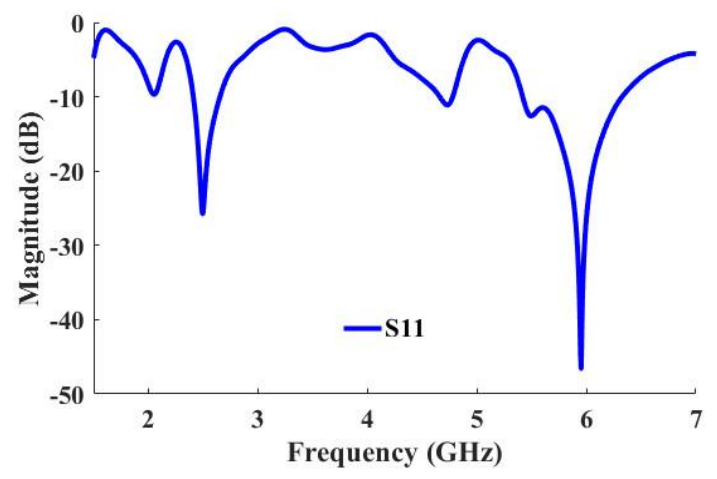

Figure 5. Reflection coefficient of the proposed antenna

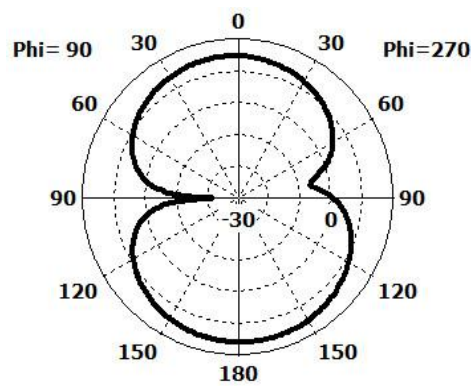

(a)

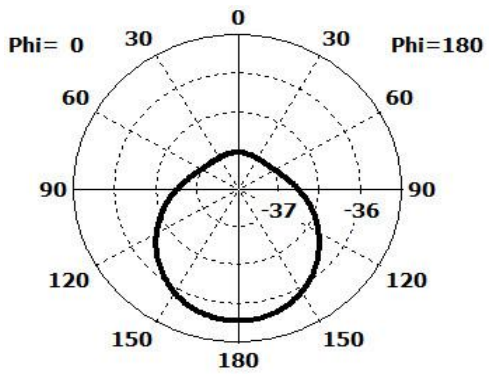

(b)

Figure 6. Radiation pattern of the proposed antenna at $2.45 \mathrm{GHz}$, (a) H-plane, (b) E-plane 


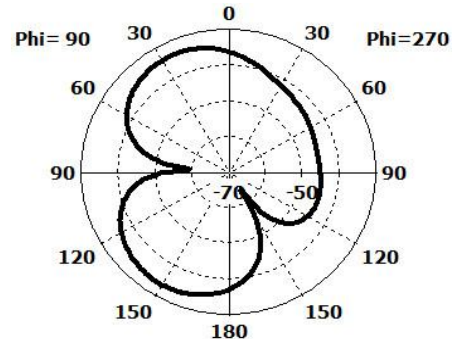

(a)

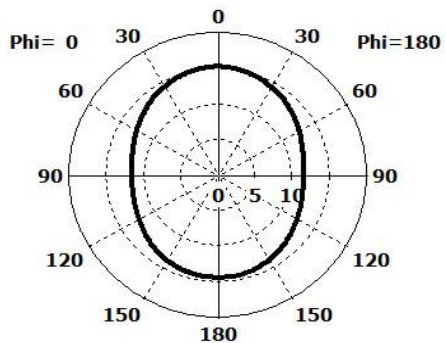

(b)

Figure 7. Radiation pattern of the proposed antenna at $5.8 \mathrm{GHz}$, (a) H-plane, (b) E-plane

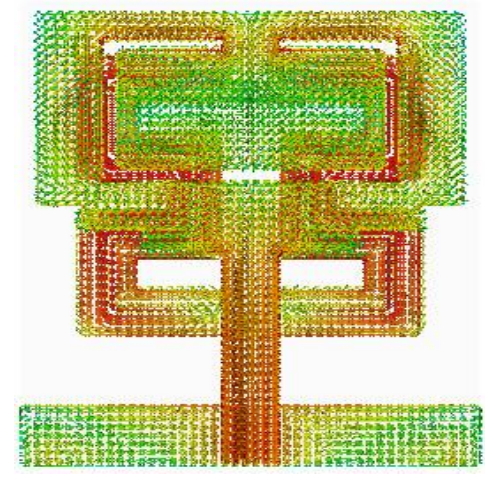

(a)

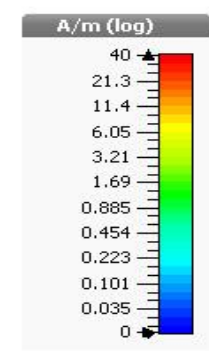

Figure 8. Current distribution of the proposed antenna at, (a) $2.45 \mathrm{GHz}$, (b) $5.8 \mathrm{GHz}$

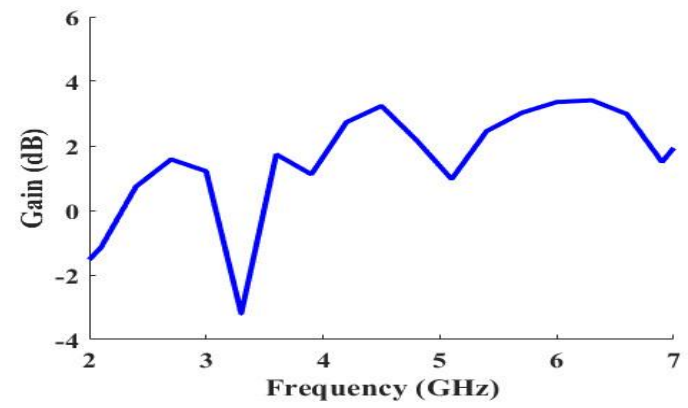

Figure 9. Gain over frequency of the proposed antenna

\section{CONCLUSION}

In this paper, a dual-band antenna for RFID applications using a partial mass plan loaded by a new metamaterial structure was presented. The metamaterials cell has been studied in order to extract its effect parameters to verify its metamaterials effect. The proposed antenna was designed on an FR4 substrate having a relative permittivity of 4.4 and tangential losses of 0.025 . It has a miniature size of $32 \mathrm{~mm} \times 26 \mathrm{~mm} \times 1.6 \mathrm{~mm}$ and good performance. The presented antenna has a good gain of $1.3 \mathrm{~dB}$ at the first frequency band and $3.8 \mathrm{~dB}$ at the second frequency band. Wide bandwidths about $230 \mathrm{MHz}$ at $2.45 \mathrm{Ghz}$ and about $400 \mathrm{MHz}$ at $5.8 \mathrm{GHz}$ were achieved using steps at the bottom of the patch. This antenna is a good solution for RFID handheld applications.

\section{REFERENCES}

[1] F. Al-Naima and H. Ameen, "Design of an RFID based s students/Employee Attendance System," Majlesi Journal of Electrical Engineering, vol. 10, No. 1, pp. 23-33, 2016.

[2] A. Ennajih, J. Zbitou, M. Latrach, A. Errkik, and R. Mandry, "A new dual band printed metamaterial antenna for RFID reader applications," International Journal of Electrical and Computer Engineering (IJECE), vol. 7, no. 6, pp. 3507-3514, 2017, doi: 10.11591/ijece.v7i6.pp3507-3514. 
[3] A. E. Hamraoui, E. H. Abdelmounim, J. Zbitou, H. Bennis, and M. Latrach, "A new Design of a CPW-Fed DualBand Monopole Antenna for RFID Readers," International Journal of Electrical and Computer Engineering, vol. 8, no. 2, pp. 1040-1047, 2018, doi: 10.11591/ijece.v8i2.pp1040-1047.

[4] H. Tizyi, F. Riouch, A. Tribak, A. Najid, and A. Mediavilla, "CPW and Microstrip Line-Fed Compact Fractal Antenna for UWB-RFID Applications,” Progress in Electromagnetics Research C, vol. 65, pp. 201-209, 2016, doi: 10.2528/PIERC16041110.

[5] S. Ajami and A. Rajabzadeh, "Radio Frequency Identification (RFID) Technology and Patient Safety," Journal of Research in Medical Sciences, vol. 18, No. 9, pp. 809-813, 2013.

[6] A. Hashemi, A. H. Sarhaddi, and H. Emami, "A Review on Chipless RFID Tag Design,” Majlesi Journal of Electrical Engineering, vol. 7, No. 2, pp. 68-75, 2013.

[7] S. Bhattacharjee, R. Saha, and S. Maity, "Metamaterial based patch antenna with omega shaped slot for RFID system," International Conference on Advances in Engineering \& Technology Research (ICAETR-2014), 2014, pp. 1-5, doi: 10.1109/ICAETR.2014.7012910.

[8] A. E. Hamraoui, E. H. Abdelmounim, J. Zbitou, A. Errkik, H. Bennis, and M. Latrach, "A Dual-Band Microstrip Slot Antenna Reader for UHF and Microwave RFID Applications," TELKOMNIKA Telecommunication Computing Electronics and Control, vol.16, no.1, pp. 94-101, 2018, doi: 10.12928/TELKOMNIKA.v16i1.7310.

[9] D. Hamzaoui, T. P. Vuong, F. Djahli, and G. I. Kiani, "Metamaterial RFID tag designs for long read range," IEEE International Symposium on Antennas and Propagation \& USNC/URSI National Radio Science Meeting, 2015, pp. 1764-1765, doi: 10.1109/APS.2015.7305271.

[10] J. I. L. Araujo et al., "Flexible UHF RFID Tag Gain Enhancement using Metamaterial Structure," 2019 4th International Symposium on Instrumentation Systems, Circuits and Transducers (INSCIT), 2019, pp. 1-4, doi: 10.1109/INSCIT.2019.8868821.

[11] N. Bahari, M. F. Jamlos, and M. M. Isa, "Gain enhancement of microstrip patch antenna using artificial magnetic conductor," Bulletin of Electrical Engineering and Informatics (BEEI), vol. 8, no. 1, pp. 166-171, 2019, doi: 10.11591/eei.v8i1.1409.

[12] K. P. Vinay, B. Ramesh, L. B. Prasad, ND D. V. R. K. Reddy, "Design of Microstrip Patch Antennafor RFID Reader Applications," Proceedings 2ndInternational Conference on Micro-Electronics,Electromagnetics and Telecommunications Lecture Notes in Electrical Engineering, Springer, Singapore, 2017, vol. 434, pp. 529-536.

[13] A. Ennajih, B. Nasiri, J. Zbitou, A. Errkik, and M. Latrach, "A Novel Design of Miniaturized Tag Antenna loaded With Metamaterial Spiral Split Ring Resonator," International Journal of Intelligent Engineering and Systems, vol.12, no.2, pp. 12-21, 2019, doi: 10.22266/ijies2019.0430.02.

[14] A. Ennajih, B. Nasiri, J. Zbitou, A. Errkik, and M. Latrach, "A Wearable UHF RFID Tag Antenna-based Metamaterial for Biomedical Applications," Bulletin of Electrical Engineering and Informatics (BEEI), vol. 9, no.2, pp. 676-684, 2020, doi: 10.11591/eei.v9i2.1661.

[15] I. Frigui, M. S. Karoui, H. Ghariani, and M. Lahiani, "New Folded Tag Antenna with Chanel Shaped Metamaterial," International Journal on Communications Antenna and Propagation, vol.6, no.6, pp. 375-380, 2016, doi: 10.15866/irecap.v6i6.10867.

[16] M. B. Yadav, B. Singh, and V. S. Melkeri, "Design of rectangular microstrip patch antenna with DGS at 2.45 GHz," International conference of Electronics, Communication and Aerospace Technology ICECA, 2017, pp. 367370, doi: 10.1109/ICECA.2017.8203706.

[17] G. Varamini, A. Keshtkar, and M. N. Moghadasi, "Compact and Miniaturized Microstrip Antenna Based on Fractal and Metamaterial Loads with Reconfigurable Qualification," AEU-International Journal of Electronics and Communications, vol. 83, pp. 213-221, 2018, doi: 10.1016/j.aeue.2017.08.057.

[18] C. Gu, et al., "Dual-Band Electronically Beam-Switched Antenna Using Slot Active Frequency Selective Surface," IEEE Transactions on Antennas and Propagation, vol. 65, no. 3, pp. 1393-1398, 2017, doi: 10.1109/TAP.2016.2647578.

[19] Z. A. Abdul Hassain, A. A. AL-Behadili, and A. R. Azeez, "First Order Parallel Coupled BPF with Wideband Rejection based on SRR and CSRR," TELKOMNIKA Telecommunication Computing Electronics and Control, vol. 17, no. 6, pp. 3027-3043, 2019, doi: 10.12928/TELKOMNIKA.v17i6.10790.

[20] D. Pattar, P. Dongaokar, and S. L. Nisha, "Metamaterial for design of Compact Microstrip Patch Antenna," in 2020 IEEE Bangalore Humanitarian Technology Conference, pp. 1-4, 2020, doi: 10.1109/B-HTC50970.2020.9297830.

[21] M. B. Ghandehari and M. Jahanbakht, "Design and Fabrication A Metamatrial based Absorber for GSM and DCS Band Application" International Journal of Electrical and Electronic Engineering and Telecommunications, vol. 6, no. 2, pp. 1-8, 2017.

[22] V. Veselago, "The Electrodynamics of Substances with Simultaneously Negative Values of $\varepsilon$ and $\mu$," Soviet Physics-Uspekhi, vol. 10, no. 4, pp. 509-514, 1968, doi: 10.1070/PU1968v010n04ABEH003699.

[23] J. B. Pendry, A. J. Holden, W. J. Stewart, and I. Youngs, "Extremely Low Frequency Plasmons in Metallic Mesostructures," Physical Review Letters, vol. 76, no. 25, pp. 4773-4776, 1996, doi: 10.1103/PhysRevLett.76.4773.

[24] J. B. Pendry, A. J. Holden, D. J. Robbins, and W. J. Stewart, "Magnetism from conductors and enhanced nonlinear phenomena," IEEE Transactions on Microwave Theory and Techniques, vol. 47, no. 11, pp. 2075-2084, Nov 1999, doi: 10.1109/22.798002.

[25] A. Ennajih, J. Zbitou, M. Latrach, A. Errkik, A. Tajmouati, and L. El Abdellaoui, "A New Design of UHF RFID Tag Antenna Based on Negative Index Metamaterial," In the 2nd International Conference on Computing and Wireless Communication Systems, 2017, pp 1-6, doi: 10.1145/3167486.3167488. 